\title{
The use of ECT and 6PBP tests to evaluate fracture behavior of adhesively bonded steel/epoxy joints under Mode-III and Mixed Mode III/II
}

Farhad Asgari Mehrabadi

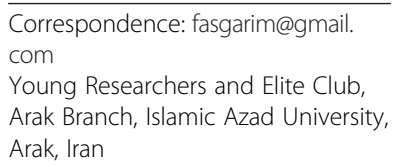

Correspondence: fasgarim@gmail. com

Young Researchers and Elite Club, Arak Branch, Islamic Azad University, Arak, Iran

\begin{abstract}
Evaluation of fracture energy of adhesive joints under mode-III and mixed-mode II//I is a key issue when failure analyses have to be performed. It is thus useful to determine fracture toughness under mode-III and characterization of crack front behavior of bonded joints under mixed-mode III/II loading conditions, which were the overall goal of this paper. For this purpose, edge crack torsion (ECT) and six-point bending plate (6PBP) tests were employed using steel/epoxy adhesive joint. The experimental tests were performed under displacement control and three types of configurations were tested to achieve different mixed-mode ratios. Test results showed considerable linearity before the maximum load point both under pure mode III and mixed-mode III/II; also, failure examination indicated that dominate failure under tearing mode was adhesive/adherend interface, which will be discussed in detail. The experimental tests were numerically simulated and virtual crack closure technique (VCCT) was employed to reproduce behavior of crack front propagation. Both experimental compliance method and finite element analysis proved applicable for the fracture mechanism of adhesive assemblies under mode-III and mixed-mode III/II.
\end{abstract}

Keywords: Adhesive joint; ECT; 6PBP; Finite element analysis; Fracture toughness

\section{Background}

Structural bonding is now a well-known assembly technique used in many industrial sectors which includes aerospace, automobiles, electrical, electronics, packaging, etc. Adhesive bonding offers considerable advantages compared with traditional forms of joining, such as bolting, riveting, and welding like giving high stiffness, strength and fatigue life, easily being automated and not requiring secondary operations for surface finishing to attain smooth exterior surfaces which result in time and cost efficiency. In the transportation industry and more specifically in the aerospace and automotive industries, this assembly technique is now used to:

- Improve energy management capability and enable using advanced high strength steel,

- Enable down-gauged steel and multi-material construction,

- Reduce the number of spot-welds, and

- Improve acoustics by increasing stiffness of the structure body, durability by overcoming fatigue problems and longtime durability by an anticorrosion barrier. 
A particular issue with the integrity of adhesive joints is the presence of cracks and flaws in the as-manufactured adhesive bond-line. The presence of these defects, at least in some scales, seems inevitable and propagation of such cracks/flaws has the potential of affecting the service life of the adhesively bonded joints and even causing catastrophic failure of bonded structures in service. Hence, a better understanding of crack propagation behavior under realistic types of combined (in-out of plane shear stress components) service loading is an important aspect of evaluating the potential performance of adhesively bonded joints.

In principle, crack propagation can be described using a fracture mechanics approach. Fracture characterization of bonded joints under pure mode-I has been extensively studied by several authors. Double cantilever beam (DCB) and tapered DCB (TDCB) tests are the most widely used methods for measuring mode-I fracture toughness [1-4]. Three-point bending of adhesively bonded end notched flexure (ENF) has shown to be the preferred test technique for obtaining mode-II critical strain energy release rate [5-9]. Mode-II crack propagation has received some attention with the development of four-point bend end-notch flexure (4ENF) and end-loaded split (ELS) [5,10], which induce stable crack propagation.

Various test specimens have been used by researchers for mixed-mode I/II fracture experiments considering varies thicknesses of adhesive layer [11-14].

As is known, crack growth could occur in any ratio of mode-I and II components of the strain energy release rate. Therefore, in addition to the pure mode tests, mixed-mode crack propagation tests have to be also carried out. The mixed-mode bending (MMB) test is now the most widely used method for investigating mixed-mode I/II fracture behavior [15-17]. This test is a combination of DCB test (pure mode I fracture) and ENF test (pure mode-II fracture), which allows for studying any combination of modes I and II. Arcan test is another useful method that has been previously employed to evaluate mixed-mode I/II fracture behavior of bonded assemblies [18].

Numerous works have been published on characterizing the performance of adhesive joints under mode-I, mode-II and mixed-mode I/II loading; however, they have not provided a basis for conservative and safe design under more complex loadings. Hence, the need for more complicated fracture characterization becomes unavoidable.

To the best knowledge of the present author, little mode-III and mixed-mode III/II experiments on fracture behavior of adhesive bonded joints have been reported in the literature [19-23]. Therefore, the objective of this study was to investigate mode-III and mixed-mode III/II fracture properties of adhesively bonded steel/epoxy joints. For this purpose, modification of the ECT specimen was used as proposed by Li [24] and 6PBP specimen [25] was employed to evaluate mode III and mixed-mode III/II in order. The strain energy release rate distribution along the crack advance front was analyzed using a three-dimensional finite element model. The stress intensity factors for ECT and 6 PBP specimens were also investigated using finite element analysis.

\section{Methods}

The studied adhesive was a two-part epoxy system, AD-314 from Mokarrar Engineering Materials (Mokarrar ${ }^{\bullet}$, Iran) (Table 1). This is a Bisphenol (A) based epoxy with a Polyamine hardener. The substrate is a low carbon steel $(E=200 G P a$ E Poisson's 
Table 1 Mechanical properties of adhesive [26]

\begin{tabular}{|c|c|c|c|c|}
\hline & $\mathrm{E}(\mathrm{GPa})$ & $v$ & $\begin{array}{l}\text { Tensile strength } \\
\text { at } 25^{\circ} \mathrm{C}(\mathrm{MPa})\end{array}$ & $\begin{array}{c}\text { Lap Shear } \\
\text { strength (MPa) }\end{array}$ \\
\hline Adhesive (epoxy AD-314) & 2.5 & 0.3 & 20 & 12 \\
\hline
\end{tabular}

ratio $=0.3)$. The surface treatment was performed by grit blasting with corundum (120\#) and cleaned with acetone to increase its adhesion and avoid adhesive failures. The space for adhesive was formed by separating the adherends by a distance of $t_{a d h}=0.4 \pm$ $0.05 \mathrm{~mm}$ in the perpendicular direction, a distance that was controlled and kept constant while curing by brass shims while a non-adhering film (Teflon film with $0.076 \mathrm{~mm}$ thickness) was used during the curing process of the adhesive; thereafter, it was inserted into the interface of the adhesive layer in order to produce the starter crack. The cure cycle recommended by Mokarrar ${ }^{\circ}$ was applied here for 7 days at room temperature in order to achieve peak of strength.

The ECT test technique proposed here was a torsion test of a rectangular plate with an edge crack at the mid-plane of adhesive layer in five crack length of $\mathrm{a}_{0}=10,15,20$, 25, $30 \mathrm{~mm}$ (Figure 1).

For the sake of clarity and conciseness, the present analysis focused on three types of the configurations adopted for 6PBP tests, which corresponded to the limit mode mix ratios (Figure 2):

i. Type I: $\mathrm{S}=140 \mathrm{~mm}, \mathrm{~d}=35 \mathrm{~mm}$.

ii. Type II: $\mathrm{S}=120 \mathrm{~mm}, \mathrm{~d}=55 \mathrm{~mm}$.

iii. Type III: $\mathrm{S}=90 \mathrm{~mm}, \mathrm{~d}=70 \mathrm{~mm}$.

For each joint type, three specimens were examined under ambient laboratory conditions. Axial compression loads were applied using a universal testing machine (GOTECH AL-7000L) with $10 \mathrm{kN}$ load cell capacity. All the specimens were loaded up to failure in the displacement rate of $0.5 \mathrm{~mm} / \mathrm{min}$. This slow rate allowed crack propagation to

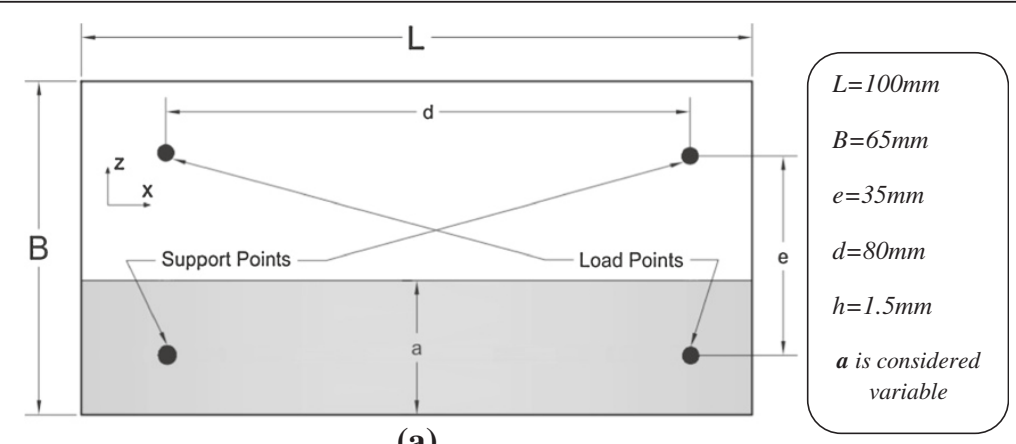

(a)

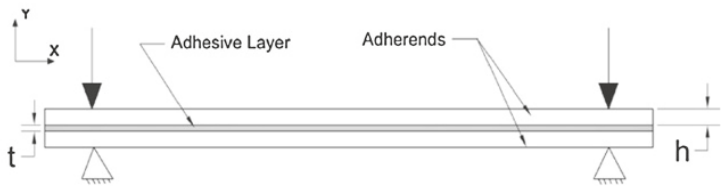

(b)

Figure 1 Bonded ECT specimen geometry (a) Top view (b) front view. 


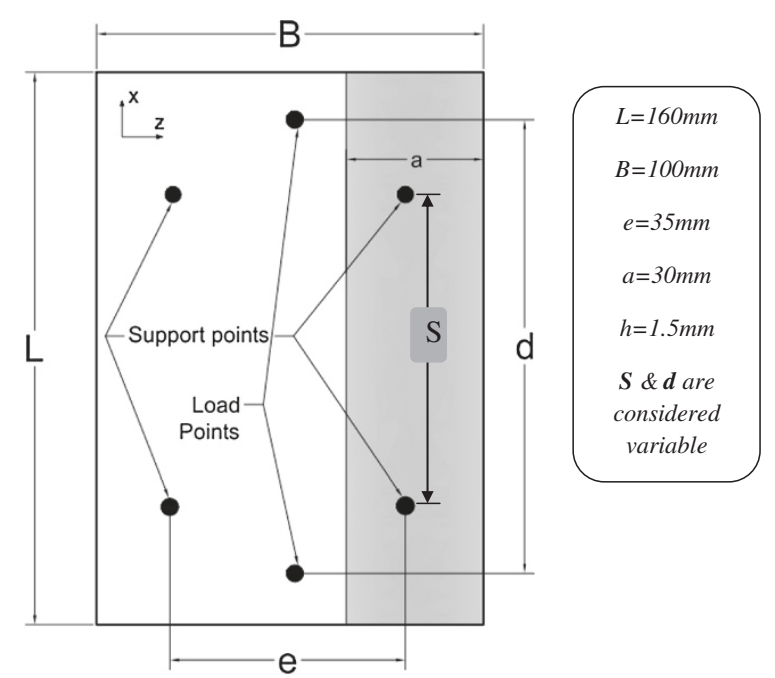

(a)

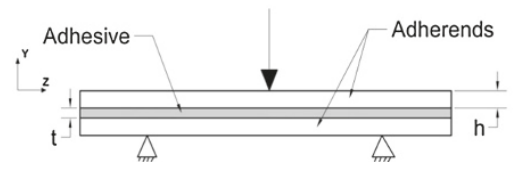

(b)

Figure 2 Schematic representation of the 6PBP test (a) Top view (b) front view.

be stable so that fracture process zone (FPZ) in crack tip can be form slowly to avoid unstable crack advance.

The test used here for mode-III fracture consisted of a simple set-up with two support pins positioned at diagonally opposite corners of specimen and loaded by two pins located at the two remaining corners attached to load frame, as shown in Figure 3(a). The test fixture was designed so that two corners of the plate were supported and the loading frame produced a pair of couples that induced opposite twisting of the panels and the

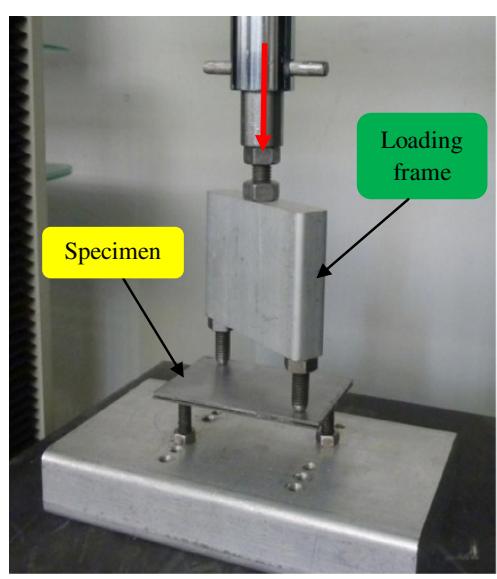

(a)

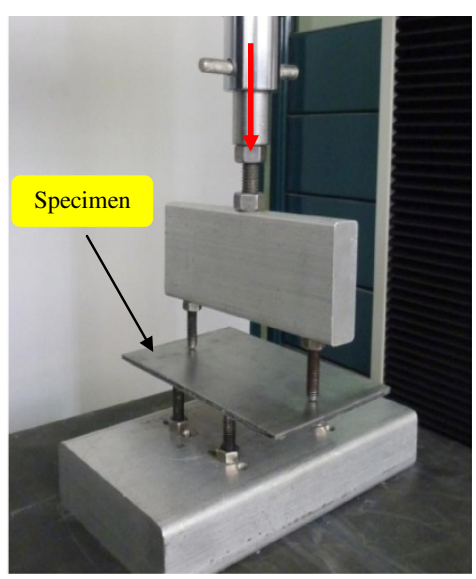

(b)

Figure 3 Experimental test set-up (a) ECT (b) 6PBP. 
characteristic mode-III deformation around the crack tip. Previously, this test set-up was employed to determine interlaminar fracture behavior of composite laminates [27].

In the case of mixed-mode III/II, the basic idea behind the development of the present test was to generate both modes by bending [25]. In these circumstances, 6PBP specimens (Figure 3(b)) were considered a reasonable solution for creating mixed-mode crack growth III/II. According to Figure 3, a special rig transferred bending load on both sides of specimen while the specimen rested on 4 mid-supports; so, it was seen that this configuration promoted crack advances near the edges (along mid-plane of adhesive layer). Furthermore, it was able to generate high mode-III and mode-II when high $S$ and small $d$ values (Figure 2) were adopted. Also, it seemed that 6PBP test was a useful and simple test for characterizing the mixed-mode III/II fracture of bonded assemblies.

ECT and 6PBP tests were conducted to determine the load-displacement behavior and the mode-III and mixed-mode III/II fracture behaviors of adhesive joints.

The methods and equations used in the present work for the analysis of the fracture mechanics data from the investigated ECT specimens is summarized in this section. In linear-elastic fracture mechanics (LEFM), the strain energy release rate (SERR) is directly derived from:

$$
G=\frac{P^{2}}{2 B} \frac{d C}{d a}
$$

where $B$ is the specimen width, $a$ the crack length obtained with the applied load $P$ and corresponding displacement $\delta$, and $C$ the specimen compliance. Standard methods for the SERR calculation are based on this equation, the difference between them basically being the way in which the derivative $d C / d a$ is obtained.

The method used in this study is the compliance calibration method which employs a multi-specimen compliance calibration procedure. In this paper, the method is called CC method.

Compliance of each specimen is plotted as a function of crack length. Linear regression analysis is performed to determine the constants, $A$ and $m$. Compliance and fracture toughness are calculated using the following expressions [24]:

$$
\frac{1}{C}=A-m a
$$

The Irwin-Kies relation then gives [28]:

$$
G_{I I I}=\frac{m P^{2}}{2 B(A-m a)^{2}}
$$

Assuming that all energy is released within the region delimited by the positions of the pins and that it is pure mode-III. Eq. (3) has the same form of the plate theory (PT) based expression derived by Lee [29], which predicts:

$$
A=\frac{32 \mu_{x y, 0} h^{3} B}{3 d e^{2}}, \quad m=\frac{32 \mu_{x y, 0} h^{3}}{3 d e^{2}}\left(1-\frac{\mu_{x y, 1}}{4 \mu_{x y, 0}}\right)
$$

where $\mu_{x y, 0}$ and $\mu_{x y, 1}$ designate the classical lamination theory (CLT) torsional shear moduli of the uncracked and cracked parts of the specimen, respectively. 
Naturally, mode-III condition using ECT is more complex than in modes I and II fracture tests which requires specimens with different crack lengths. In fact, the crack position cannot be monitored during ECT tests and the crack length cannot be varied by repositioning a single specimen. However, this method bears errors inherent to specimen variability and increases substantially test costs. In order to overcome those drawbacks, a new data reduction scheme based on the compliance versus crack length relation is proposed by de Moura et al. [30]. Other problems may affect mode-III and mixed-mode III/II tests, e.g. identifying correctly the initiation failure point. The commonly employed non-linearity and maximum load criteria can give substantially different results.

Therefore, considerable research is still needed to validate the ECT and 6PBP tests for measuring $G_{I I I c}$ of adhesive joints. The present study aimed at evaluating its adequacy for adhesively bonded steel/epoxy joints by combining numerical analyses and experimental tests.

3D finite element models were established for the ECT and 6PBP specimens using the software ANSYS.12 [31]. A typical crack, as schematically illustrated in Figure 1, was introduced in the FEA models between the mid-plane of adhesive layers. The element type SOLID45 was used and, based on a parametric study, a mesh size of $0.4 \mathrm{~mm}$ for the crack increment $(\Delta \mathrm{a})$ was selected for both joint types. In order to avoid the mutual penetration of the adherends in mode III and mixed-mode fracture, the correlated contact (CONTA174) and target (TARGE170) elements were employed for the two crack surfaces. The ECT model comprised 4680 elements and the 6PBP model 5520 elements. The boundary conditions of the testing configuration were simulated so that were the same as those illustrated in Figures 1 and 2. Experimental load values corresponding to arbitrarily selected crack lengths were used as input for calculation of the corresponding nodal displacements and forces. Non-linear-elastic analysis (for existing of contact elements) was performed and the specimen elongations, nodal forces and nodal displacements were calculated. Also, based on parametric study, mesh fine and type of elements (using more higher order elements) do not affected on values of nodal force and displacements on crack tip and in order to model the specimens in this paper, just around the crack tip and along the crack over width of the specimens, the finer mesh has been used for VCC method.

The virtual crack closure technique relies on accurate numerical calculation of the nodal forces at the crack tip $\left(Z_{L i}, X_{L i}\right.$ and $\left.Y_{L i}\right)$ and the displacements of the adjacent nodes $\ell$ and $\ell^{*}$ ( $w_{L \ell}, w_{L \ell}{ }^{*}, u_{L \ell}, u_{L \ell}{ }^{*}, v_{L \ell}$ and $\left.v_{L \ell}{ }^{*}\right)$, as shown in Figure 4 for a 3-dimensional (3D) model. $G_{I}$ and $G_{I I}$ and $G_{I I I}$ are then calculated as [32]:

$$
\begin{aligned}
& G_{I}=\frac{1}{2 \Delta a}\left[Z_{L i} \cdot\left(w_{L \ell}-w_{L \ell^{*}}\right)\right] \\
& G_{I I}=\frac{1}{2 \Delta a}\left[X_{L i} \cdot\left(u_{L \ell}-u_{L \ell^{*}}\right)\right] \\
& G_{I I I}=\frac{1}{2 \Delta a}\left[Y_{L i} \cdot\left(v_{L \ell}-v_{L \ell^{*}}\right)\right]
\end{aligned}
$$

where $\Delta \mathrm{a}$ is the crack increment, which is equal to the element size at the crack tip.

\section{Results and Discussions}

The typical load-displacement response of the ECT and 6PBP specimens is shown in Figure 5 (ECT with $\mathrm{a}=15 \mathrm{~mm}$, test no. 2 and 6PBP of type III, test no. 3 based on 


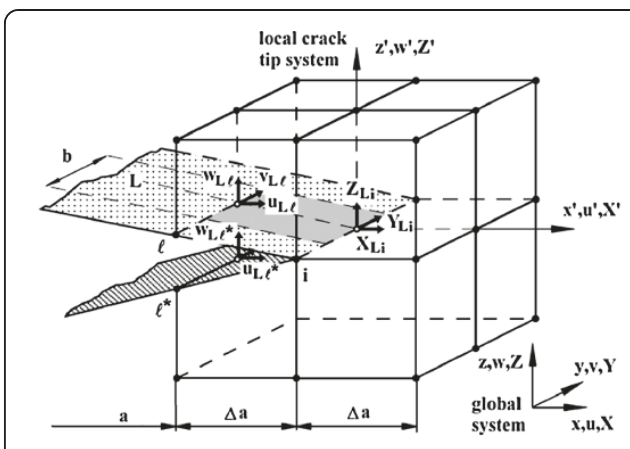

(a)

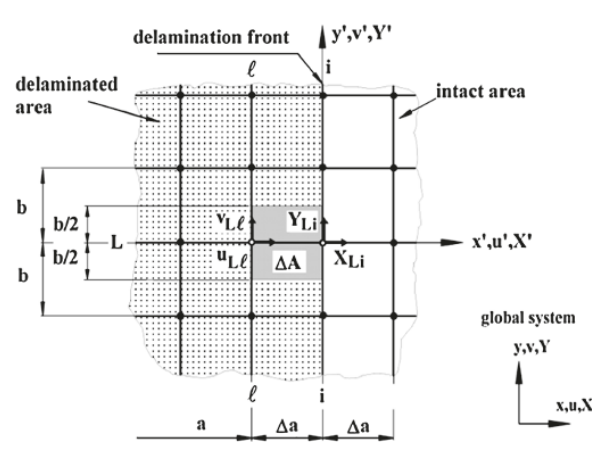

(b)

Figure 4 VCC technique for four noded plate/shell and eight noded solid elements (a) 3D view (b) top view of upper surface [32].

Table 2). Loading was manually stopped when the two parts of joint were separated from each other. All the curves followed an almost linear increasing trend up to the maximum load and then decreased. The alternating increasing and decreasing segments of this pattern corresponded to the alternating phases of crack initiation and crack arrest. The unloading parts were omitted for clarity reasons.

ECT and 6PBP tests were repeated at least three times for each crack length and loading mode ratios, respectively. Then, average values of critical maximum loads were extracted to be employed in FE analysis (Table 2). Moreover, no plastic deformation was observed in the adherends after unloading and all the tested samples were essentially linear elastic to failure.

Investigating the failure locus is very important since cracks can switch from adhesive to the adhesive/adherent interface. In such cases, the fracture envelope would be an effective one since it lumps different phenomena together. For this purpose, the fracture surfaces were examined. A photograph of ECT tested specimen is shown in Figure 6 as an example. As can be seen, adhesive/adherent interface failure was uniformly distributed over the entire fracture surface, except very small areas at the longitudinal edges, in which the crack path advanced in the middle of the adhesive layer.

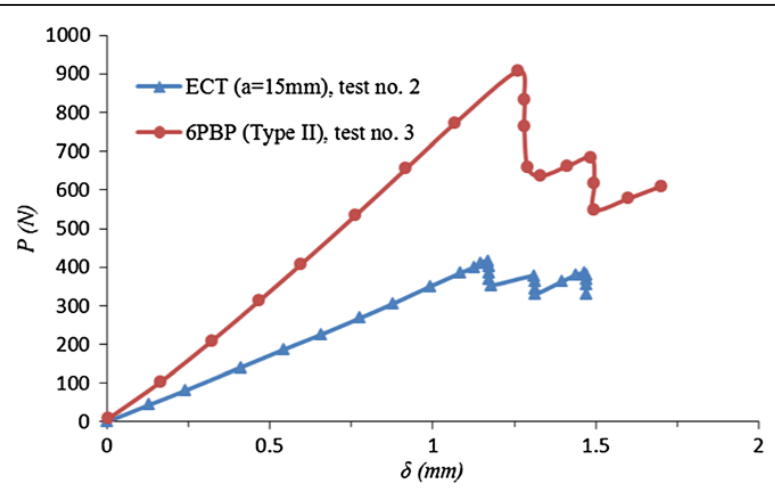

Figure 5 Typical experimental load-deflection results of the ECT and 6PBP tests. 
Table 2 Fracture loads of ECT and 6PBP tests

\begin{tabular}{|c|c|c|c|c|c|c|c|c|c|}
\hline & \multirow{2}{*}{$\begin{array}{c}\text { Test } \\
\text { no. }\end{array}$} & \multicolumn{5}{|c|}{$E C T$} & \multicolumn{3}{|c|}{$6 P B P\left(a_{o}=30 \mathrm{~mm}\right)$} \\
\hline & & $a_{0}=10 \mathrm{~mm}$ & $a_{0}=15 \mathrm{~mm}$ & $a_{0}=20 \mathrm{~mm}$ & $a_{0}=25 \mathrm{~mm}$ & $a_{0}=30 \mathrm{~mm}$ & Type I & Type II & Type III \\
\hline \multirow[t]{3}{*}{ Failure load ( $N$ ) } & 1 & 495 & 505 & 407 & 373 & 352 & 910 & 1045 & 898 \\
\hline & 2 & 533 & 420 & 440 & 410 & 342 & 1140 & 841 & 935 \\
\hline & 3 & 502 & 485 & 443 & 357 & 260 & 1210 & 892 & 912 \\
\hline Mean value $(N)$ & & 510 & 470 & 430 & 380 & 318 & 1087 & 926 & 915 \\
\hline (Std.) & & (23) & (50) & (23) & (30) & (58) & $(177)$ & (119) & (20) \\
\hline
\end{tabular}


This failure was mostly observed in pure mode-III tests where the crack path switched into the interface. Actually, crack kinking was a significant observation in the ECT test so that almost in all the studied specimens, the initial crack in the adhesive layer quickly turned and propagated along the adhesive/adherend interface, which was probably caused by creating mode-III (tearing) helping torsion of the specimen during the test.

Figure 7 shows that failures occurred in 6PBP tested specimens. As shown in specimen type I (a) like ECT specimens, crack path was mostly in adhesive/adherent interface. In spite of type I specimen, type III showed combined cohesive and adhesive failures so that adhesive/adherend failure distributed over the middle width of specimen and cohesive failure happened along the edges. It should be mentioned that surface cleaning and treatment played important roles in causing failure modes and also strength of adhesive joints. Overall, the experimental outcome was useful for damage tolerance analyses since, in real structures with realistic loading scenarios, similar failure locus was expected.

Typically, fracture test method requires obtaining three critical strain energy release rate values. The first one is based on the load where the load-displacement curve first deviates from linearity (non-linear), $F_{N L}$. The second option is based on the maximum load, $F_{\max }$, and the third one corresponds to the point at which the actual crack initiation is visually observed by the testing personnel.

Because of warp deformation of ECT specimen during loading in mode-III condition, the crack position cannot be monitored during the tests. Also, because of brittle fracture behavior of adhesive joint in this study, the maximum point was proposed as critical load at failure (initial crack propagation) [33]. The average values of critical loads were extracted (as shown in Table 2) based on peak load criteria. Using fracture loads and corresponding displacements, compliance of ECT tested specimens was extracted to determine constants $A$ and $m$ in Eq. 2 for specimen stiffness. Figure 8 demonstrated fracture toughness behavior of pure mode-III versus crack length. It can be seen that it would lead to the increase in perceived $G_{I I I C}$ with the crack length. The mean values of critical fracture energy of maximum point criteria were achieved as $G_{I I I C}=232.5\left(\mathrm{~J} / \mathrm{mm}^{2}\right)$. In theory, it may seem that the values are representative of fracture initiation; therefore, the measured critical mode-III strain energy release rate should be constant with insert crack lengths if mode-III strain energy value is considered as a natural attribute of adhesive joints whereas fracture toughness of mode-I and mode-II conditions in

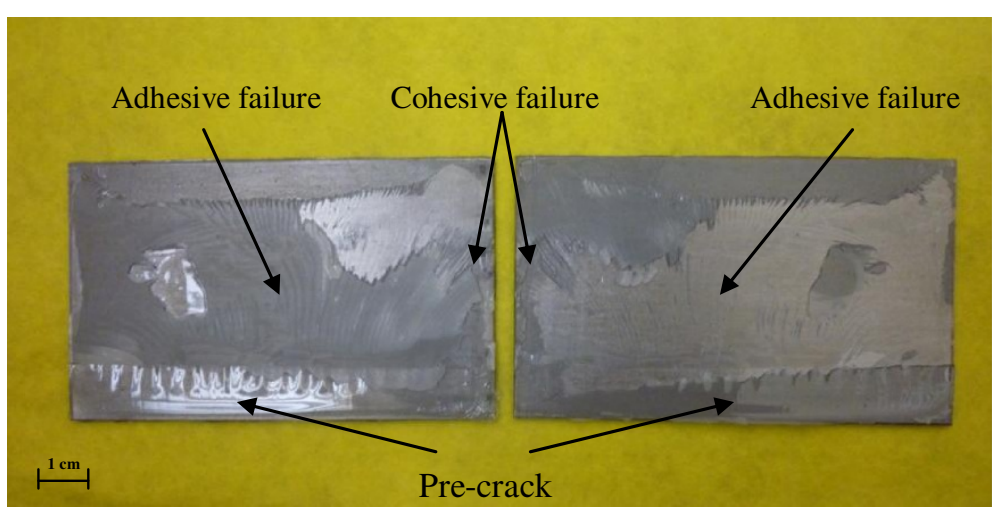

Figure 6 Photographs of the ECT fracture surfaces $(a=20 \mathrm{~mm})$. 


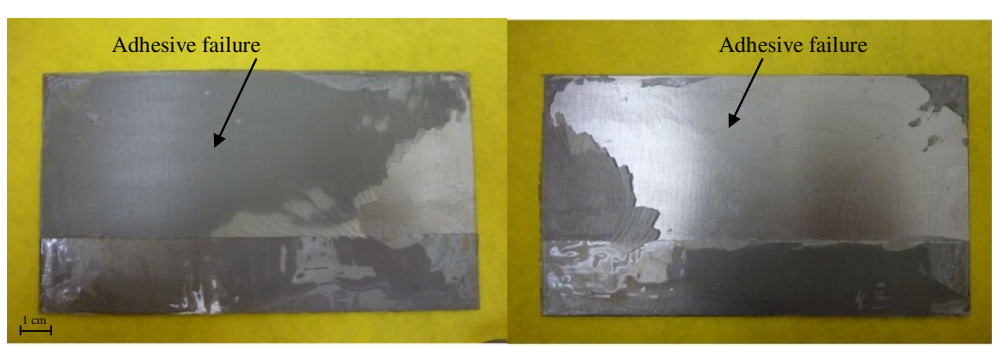

(a)

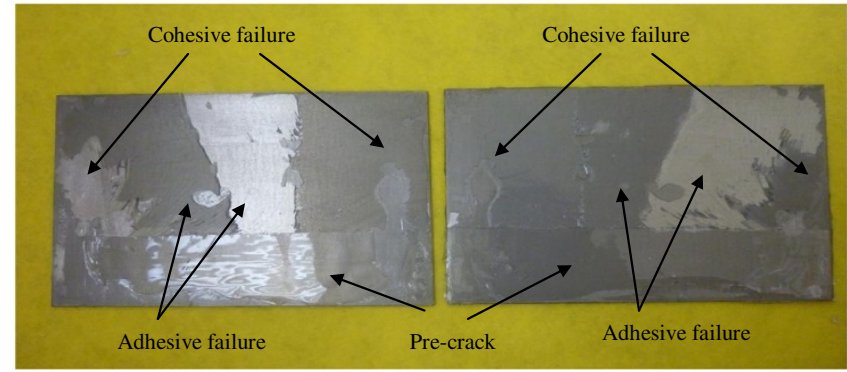

(b)

Figure 7 Photographs of the 6PBP fracture surfaces (a) Type I (b) type III.

adhesive joints indicated Stable $R$-curve behavior so that fracture toughness could be introduced by a constant value [1-10].

In this section, the loads corresponding to crack initiation in the ECT specimen are used to calculate the critical strain energy release rates through the width of specimen using non-linear elastic finite element models. Computational approaches like FEMs play an important role in detecting mechanical crack front and damage of adhesive assemblies.

For obtaining definite explanation of initial crack length dependence of $G_{I I I C}$ in the ECT test, distribution of strain energy release rates along the crack front was analyzed for five crack lengths. Figure 9 shows distribution of $G_{I I I}, G_{I I}$ and $G_{I}$ normalized by the maximum value of $G_{I I I}$. It can be seen that the mode-I component was verified to be negligible in all the crack lengths, except in region of the pins at crack length of $\mathrm{a}_{0}=20,25 \mathrm{~mm}$. Also, the mode-II component was confined to the limiting region of the pins; it was significantly smaller than the mode-III component in less

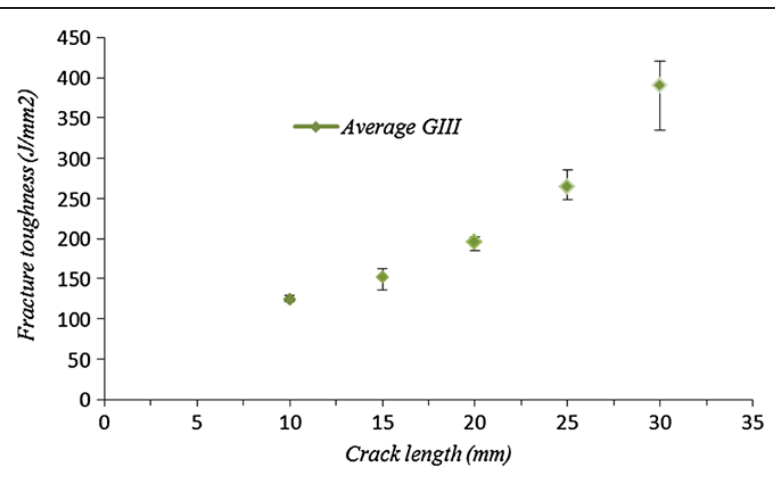

Figure 8 Plot of fracture toughness against crack length ( $R$-curve). 
crack lengths so that mode II portion increased near the pin zone with the increase of crack length.

Moreover, Figure 9 indicates that mode-III component was approximately constant over the central region of ECT specimens. However, the plateau size presenting the amount of mode-III component remained sensibly at the same level, meaning that distribution of strain energy release rates could not explain the crack length dependence of $\mathrm{G}_{\text {IIIC }}$. Similarly, crack front in mode-I showed such a behavior in adhesive joints and composite materials such as SERR had the maximum and minimum values in the middle width of adhesive layer and at edges, respectively; leaving the edges, SERR increased and approached a constant value (plateau region) and decreased while getting closer to the edges [34-36].

In spite of mode-I and mode-III, crack front distribution in mode-II was uniform with the exception of localized peaks at the specimen edge [36,37] and crack advance was linear and no difference was detected between crack length at the edges and in the center of the specimen. This point demonstrated that, in mode-III as mode-I loading, there was a higher potential for the growth of crack in the center width of adhesive pad, which indicated that a crack can grow in mode-I and mode-III without being noticed.

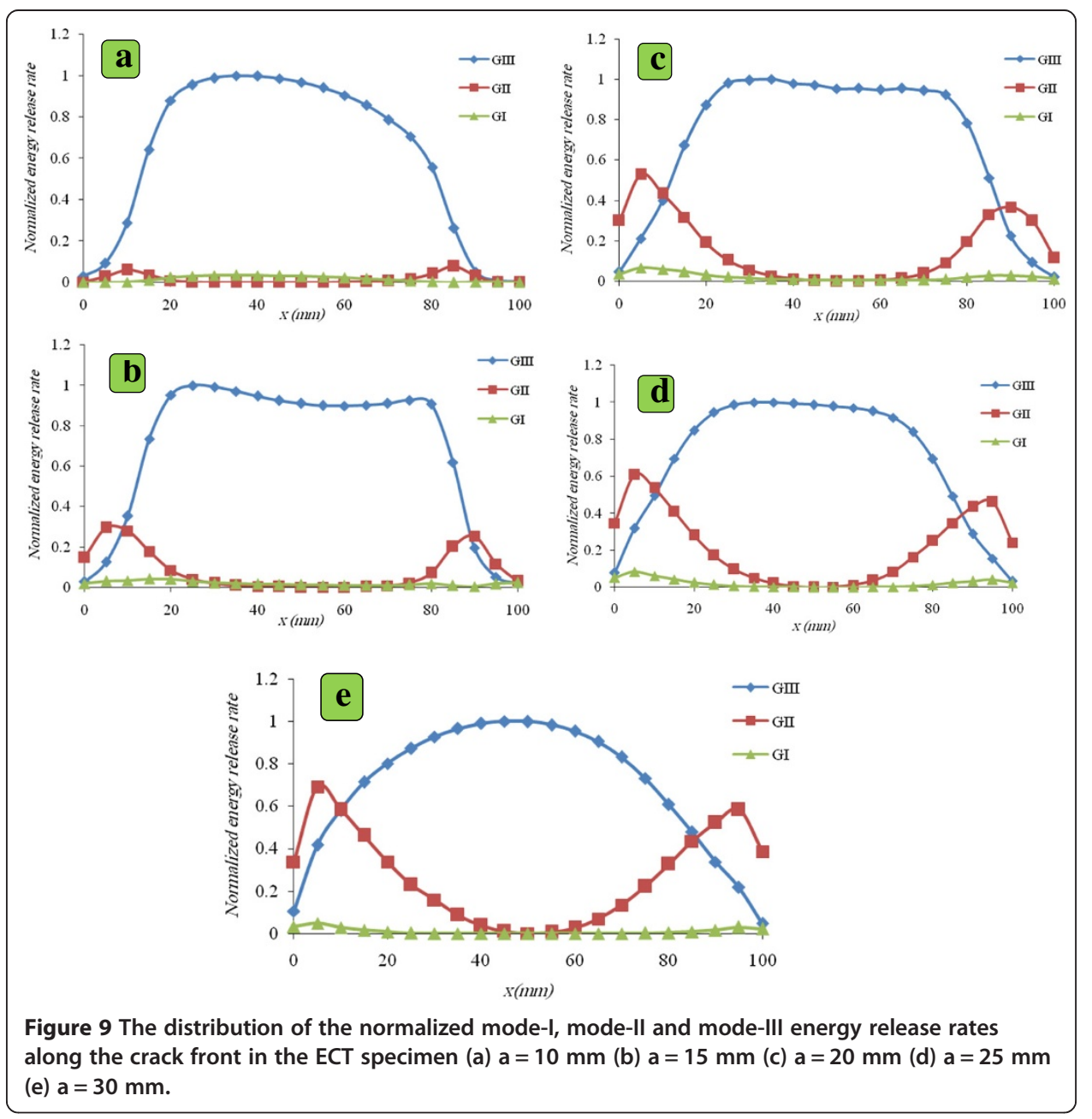




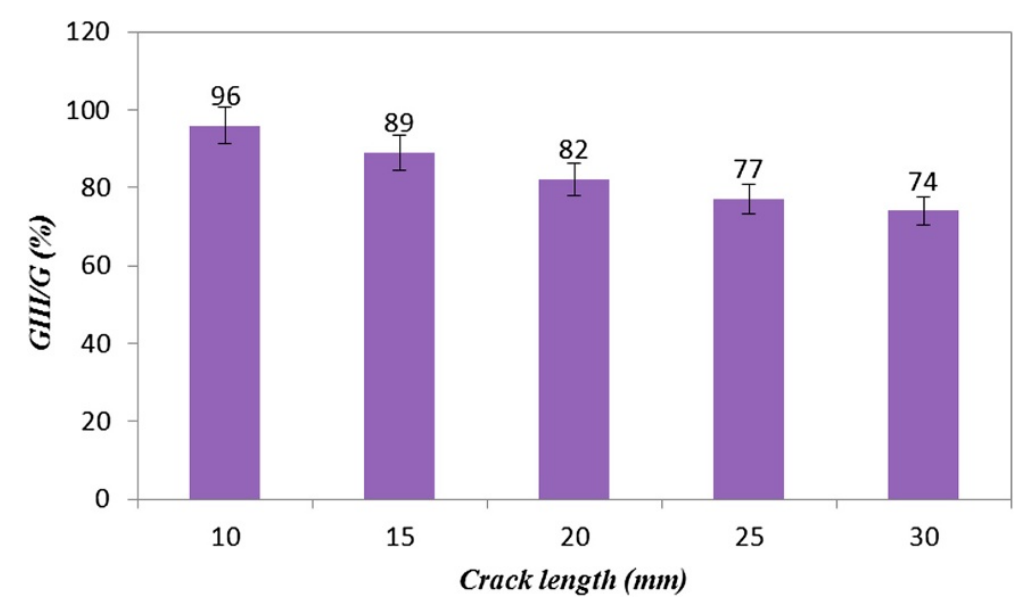

Figure 10 Percentage of mode III contributions in total energy release rate.
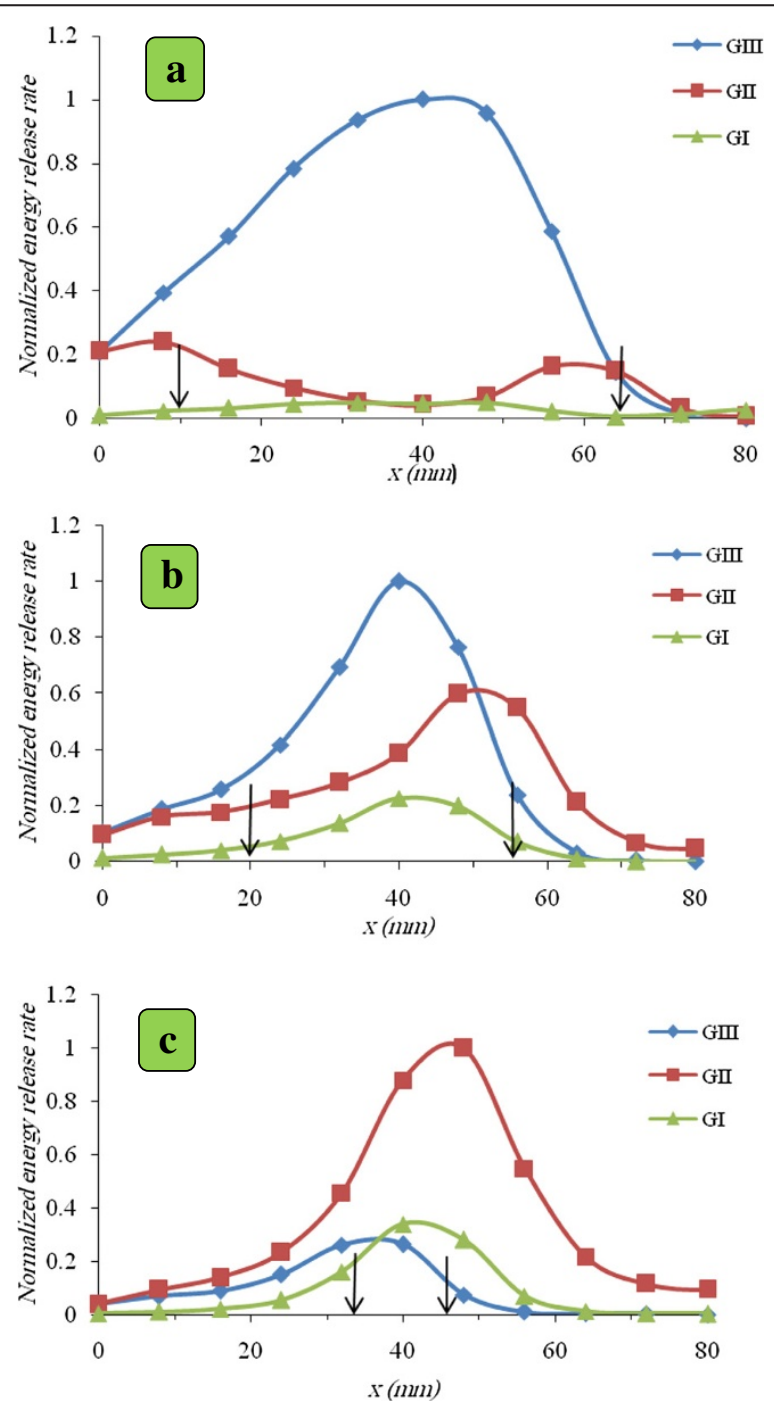

Figure 11 The distribution of the normalized mode-I, mode-II and mode-III energy release rates along the crack front in the 6PBP specimen (a) type I (b) type II (c) type III. 
This issue should be designated in designing an adhesive joint. Also, this behavior can be seen in mode-I and mode-III interlaminar fractures of multidirectional laminates [38].

In order to choose optimal geometrical configuration of the ECT specimen for a nearly pure mode-III test, a comparison was performed between mode-III contributions with the total energy release rate in different crack lengths (Figure 10). Based on the measurement indicated in Figure 10, it was found out that mode-III fracture was dominated by about $96 \%$ in the crack length of $\mathrm{a}=10 \mathrm{~mm}$.

Figure 11 shows distribution of $G_{I I I}, G_{I I}, G_{I}$ and $G$ normalized by the maximum value of $G_{I I I}$ for different mode mix ratios on three of the adapted configurations. Because of the symmetric distribution of modes I, II, III relative to half of 6PBP specimen and in order to overcome the ambiguity, crack distribution was considered in half of the specimen in which initiation was likely to occur. It can be seen that crack front showed non-uniform distribution while mode-III and mode-II components presented usual tendency to the development of curved thumbnail and sharpen-shaped delamination fronts at their peak values, respectively. Also, in spite of ECT test, mode-I contribution was verified to have a significant value, especially in type III configuration. Another result from Figure 11 was that crack initiation could be mostly estimated between load and support points. Moreover, mode-II component had the maximum value at support pins.

Figure 12 compares mode I, II and III contribution ratios in three types of 6PBP tests. Obviously, in higher $S$ and lower $d$ (Figure 11(a)), mode-III was dominant almost between load and support points $\left(G_{I I I} / G=79 \%\right)$ while, in lower $S$ and higher $d$ (Figure 11(c)), mode-II was the predominant state of crack growth $\left(G_{I I} / G=68 \%\right)$.

Furthermore, numerical results indicated that, in 6PBP test, mode-III and mode-II components can be created by controlling load and support points. Also, comparison of fracture load showed that fracture load decreased with changing mixed-mode ratio (mode-III to mode-II dominate). Nonetheless, the 6PBP test for mixed-mode III/II condition inevitably involved the non-uniform distribution of crack growth and it was also clear that mixed-mode III/II fracture required extensive investigation which should lead to the development of improved test methods.

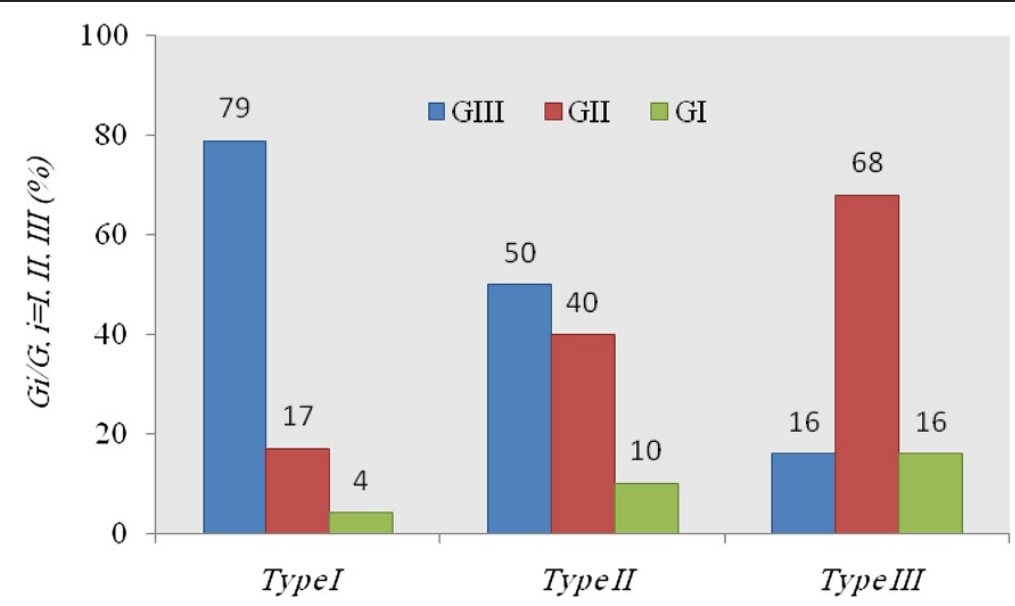

Figure 12 Comparison of mode-III, mode-II and mode-I contributions to the total energy release rate for three types of 6 PBP configuration. 


\section{Conclusions}

In this paper, a combined experimental/numerical approach was presented for the characterization of adhesive joints under mode-III and mixed-mode III/II loading conditions using ECT and 6PBP tests. The material under investigation was steel/ epoxy adhesive joint for bonding. The major conclusions resulted from experiments and numerical solutions can be summarized for the global effects as follows:

1. The results indicated that the proposed fixture (modified ECT and 6PBP tests) could be very useful for creating mode-III and mixed-mode III/II crack growth conditions for adhesive bonded joints so that an optimum configuration could give $96 \%$ mode-III contribution to the total energy release rate.

2. Based on the fracture surface examination, adhesive/adherend interface failure was the dominant failure and combination of adhesive and cohesive failure was achieved in ECT and 6PBP tests, respectively, which indicated that cohesive failure occurred when mode-II components dominated fracture state in 6PBP test.

3. It was shown that GIII increased with the crack length increase using compliance method whereas mode-I and mode-II critical fracture energy showed a stable resistant curve ( $R$-curve).

4. The finite element results showed almost stable crack growth under mode-III loading, meaning that the distribution of critical strain energy release rates could not explain crack length dependence of $G_{I I I C}$.

5. Also, numerical analysis proved that $6 \mathrm{PBP}$ test had non-uniform distribution of $G_{I I}$ and $G_{I I I}$ which resulted in non-uniform crack advance and depended on finite element methods. Also, propagation of crack initiation can be mostly estimated between load and support points.

Competing interests

The author declares that he has no competing interests.

Authors' contributions

FAM carried out the theoretical studies and Experimental tests and FE analysis. Also, FAM drafted the manuscript, read and approved the final manuscript.

\section{Acknowledgement}

The author wishes to thank the Institute of Standard (Arak, Iran) and Mr. A. Azizi for kindly provided access to their facilities for experimental tests.

Received: 29 November 2013 Accepted: 27 January 2014

Published: 07 May 2014

References

1. Steinbrecher G, Buchman A, Sidess A, Sherman D (2006) Characterization of the mode I fracture energy of adhesive joints. Int J Adhes Adhes 26:644-650

2. Ashcroft IA, Hughes DJ, Shaw SJ (2001) Mode I fracture of epoxy bonded composite joints:1. Quasi static loading. Int J Adhes Adhes 21:87-99

3. Blackman BRK, Kinloch AJ, Paraschi M, Teo WS (2001) Measuring the mode I adhesive fracture energy, $G_{C}$, of structural adhesive joints: the results of an international round-robin. Int J Adhes Adhes 23:293-305

4. de Moura MFSF, Campilho RDSG, Gonçalves JPM (2008) Crack equivalent concept applied to the fracture characterization of bonded joints under pure mode I loading. Comp Sci Tech 68:2224-2230

5. Blackman BRK, Kinloch AJ, Paraschi M (2005) The determination of the mode II adhesive fracture resistance, $G_{\| c}$ of structural adhesive joints: an effective crack length approach. Eng Frac Mech 72:877-897

6. de Moura MFSF, Campilho RDSG, Gonçalves JPM (2009) Pure mode II fracture characterization of composite bonded joints. Int J Solids Struct 46:1589-1595

7. Kim WS, Lee JJ (2009) Fracture characterization of interfacial cracks with frictional contact of the crack surfaces to predict failures in adhesive-bonded joints. Eng Frac Mech 76:1785-1799

8. Carlsson LA, Gillespie JW, Pipes RB (1986) On the analysis and design of end notched flexure (ENF) specimen for measuring mode II fracture toughness. J Compos Mater 20:594-604 
9. de Moura MFSF, Gonçalves JPM, Chousal JAG, Campilho RDSG (2008) Cohesive and continuum mixed-mode damage models applied to the simulation of the mechanical behaviour of bonded joints. Int J Adhes Adhes 28:419-426

10. Yoshihara H, Mode II (2004) R-curve of wood measured by 4-ENF test. Eng Frac Mech 71:2065-2077

11. Dollhofer J, Beckert W, Lauke B, Schneider K (2001) Fracture mechanics characterization of mixed-mode toughness of thermoplast/glass interfaces (brittle/ductile interfacial mixed-mode fracture). J Adh Sci Technol 15:1559-1587

12. Shahin K, Taheri F (2009) Fracture behaviour of adhesively bonded joints in sandwich composite beams. J Adh Sci Technol 23:1531-1546

13. Pao YH, Morman KN, Dickie RA (1990) On the effect of an interfacial layer on the fracture behavior of interface and subinterface cracks in single-lap shear joints. J Adh Sci Technol 4:503-520

14. States DN, DeVries KL (2012) Geometric factors impacting adhesive Lap joint strength and design. J Adh Sci Technol 26:89-107

15. Hafiz TA, Wahab MMA, Crocombe AD, Smith PA (2010) Mixed-mode fracture of adhesively bonded metallic joints under quasi-static loading. Eng Frac Mech 77:3434-3445

16. Ameli A, Papini M, Schroeder JA, Spelt JK (2010) Fracture R-curve characterization of toughened epoxy adhesives. Eng Frac Mech 77:521-534

17. Balzani C, Wagner W, Wilckens D, Degenhardt R, Busing S, Reimerdes HG (2012) Adhesive joints in composite laminates-A combined numerical/experimental estimate of critical energy release rates. Int J Adhes Adhes 32:23-38

18. Choupani N (2008) Interfacial mixed-mode fracture characterization of adhesively bonded joints. Int J Adhes Adhes 28:267-282

19. Sharif F, Kortschot MT, Martin RH (1995) Mode III delamination using a split cantilever beam, composite materials. Fatigue Fracture 5:ASTM STP1230

20. Fernlund G, Lanting H, Spelt JK (1995) Mixed mode II/III fracture of adhesive joints. J Compos Technol Res 17:317-330

21. Lanting H, Spelt JK (1997) Shear fracture of adhesively-bonded rigid elements. Compos Part B 28:319-329

22. Vintilescu I, Spelt JK (1998) Mixed-mode I-II-III fracture characterization of adhesive joints. J Compos Technol Res 20:129-139

23. Vintilescu I, Spelt JK (1998) Fracture load prediction of adhesive joints under mixed-mode I-II-III conditions. J Compos Technol Res 20:187-197

24. Li J, Lee SM, Lee EW, Brien TKO (1997) Evaluation of the edge crack torsion (ECT) test for mode III interlaminar fracture toughness of laminated composites. J Compos Technol Res 19:174-183

25. de Morais AB, Pereira AB (2008) Mixed mode II + II interlaminar fracture of carbon/epoxy laminates. Compos Sci Technol 68:2022-2027

26. Mokarrar Industrial group database. http://www.mokarrar.com. Accessed 21 February 2012

27. Marat-Mendes R, de Freitas M (2009) Characterization of the edge crack torsion (ECT) test for the measurement of the mode III interlaminar fracture toughness. Eng Frac Mech 76:2799-2809

28. Anderson TL (1995) Fracture mechanics: fundamentals and applications. CRC press, Boca Raton

29. Lee SM (1993) An edge crack torsion method for mode III delamination fracture testing. J Compos Tech Res 15:193-201

30. de Moura MFSF, Fernandez MVC, de Morais AB, Campilho RDSG (2009) Numerical analysis of the edge crack torsion test for mode III interlaminar fracture of composite laminates. Eng Frac Mech 76:469-478

31. Ansys (2009) ANSYS Release 12.0 Documentation. Ansys Inc. Pennsylvania, USA

32. Krueger R (2002) The Virtual Crack-Closure Technique: History, Approach and Applications. NASA/CR-2002-211628, ICASE Report No. 2002-10, NASA Langley Research Center, Hampton, Virginia, USA

33. Asgari Mehrabadi F, Khoshravan M (2013) Mode III interlaminar fracture and damage characterization in woven fabric-reinforced glass/epoxy composite laminates. J Compos Mater 47:1583-1592

34. Khoshravan M, Asgari Mehrabadi F (2012) Fracture analysis in adhesive composite material/aluminum joints under mode-l loading; experimental and numerical approaches. Int J Adhes Adhes 39:8-14

35. Pereira $A B$, de Morais $A B$, de Moura MFSF, Magalhães AG (2005) Mode I interlaminar fracture of woven glass/epoxy multidirectional laminates. Compos Part A 36:1119-1127

36. Pereira AB, de Morais AB (2008) Mixed mode I + II interlaminar fracture of carbon/epoxy laminates. Compos Part A 39:322-333

37. de Moura MFSF, Silva MAL, de Morais AB, Morais JJL (2006) Equivalent crack based mode II fracture characterization of wood. Eng Fract Mech 73:978-993

38. Szekrényes A (2009) Improved analysis of the modified split-cantilever beam for mode-III fracture. Int J Mech Sci 51:682-693

10.1186/2196-4351-2-18

Cite this article as: Asgari Mehrabadi: The use of ECT and 6PBP tests to evaluate fracture behavior of adhesively

bonded steel/epoxy joints under Mode-III and Mixed Mode III/II. Applied Adhesion Science 2014, 2:18 